\title{
Investigation of methylation and protein expression of the Runx3 gene in colon carcinogenesis
}

\author{
SHAO-YA HE ${ }^{1}$, REN-FA JIANG $^{1}$, JIE JIANG ${ }^{2}$, YANG-SHENG XIANG $^{1}$ and LING WANG $^{1}$ \\ ${ }^{1}$ Department of Gastroenterology, Anyue People's Hospital, Ziyang, Sichuan 642350; ${ }^{2}$ Department of Respiration, \\ Chongqing Sixth People's Hospital, Chongqing 404100, P.R. China
}

Received May 12, 2015; Accepted May 28, 2015

DOI: $10.3892 /$ br.2015.479

\begin{abstract}
In the present study, the methylation and protein expression of the runt-related transcription factor 3 (Runx3) gene was detected in sporadic colorectal cancer, colonic adenoma and normal colon tissue to evaluate their clinical significance in colorectal carcinogenesis. A total of 34 colonic cancer specimens, 34 colonic adenoma specimens and 34 normal colonic tissue specimens were used in the study. The $\mathrm{CpG}$ island methylation status of the Runx3 gene was detected by methylation-specific polymerase chain reaction and the protein expression of Runx3 was detected by immunohistochemistry. The results showed that the rates of methylation of the Runx 3 gene in colonic cancer and colonic adenomas were significantly higher than that in the normal colonic tissue $(23.5,20.6$ vs. $0.0 \%$; $\mathrm{P}<0.05)$. There was no significant difference in the percentage of methylation of the Runx3 gene between colonic adenoma and colonic cancer ( $\mathrm{P}>0.05)$. The positive percentage of Runx3 protein expression was significantly lower in colonic cancer compared with colonic adenoma and normal tissue $(17.7$ vs. $61.8,76.5 \%$; $\mathrm{P}<0.05)$. Methylation of the promoter CpG islands of the Runx3 gene is an important genetic event of colon carcinogenesis and may be associated with an altered protein level of Runx3.
\end{abstract}

\section{Introduction}

DNA methylation is one of the most common types of epigenetic change, whose methylation is provided by S-adenosyl methionine. With the catalytic potential of DNA methyltransferase, the cytosine of DNA at the C-5 position is converted to 5-methylcytosine, occurring at the transcriptional level, and this does not change the primary structure of DNA base modifications $(1,2)$. The methylation position is often a $5^{\prime}-\mathrm{CpG}-3^{\prime}$ dinucleotide. Extensive gene methylation exists in different tumors, and studies have found that hypermethylation occurs in human primary tumor-suppressor gene (3-5).

Correspondence to: Dr Ling Wang, Department of Gastroenterology, Anyue People's Hospital, 84 Wainan Street, Ziyang, Sichuan 642350, P.R. China

E-mail: heshaoya2014@163.com

Key words: Runx3, methylation, colonic cancer
The tumor-suppressor gene runt-related transcription factor 3 (Runx3) is an classic gene in the Runx family, with all the features attributed to this family. Runx3 regulates the growth and differentiation of epithelial cells and it is located downstream of transforming growth factor- $\beta$ (TGF- $\beta$ ). Under the guidance of the Runx proteins, Smad complexes can be transfered from the cytoplasm into the nuclei in a specific location. In cooperation with the Runx3 protein, they can induce transcription and activate target genes, so as to effect cell differentiation, cell cycle regulation, apoptosis and malignant transformation.

Runx3 is an apoptotic factor correlated with tumorigenesis and cancer progression, and research has indicated that Runx3 is involved in numerous tumorigeneses, such as gastric (6), breast (7), ovarian (8) and head and neck cancer (9). Several studies have reported Runx 3 expression in colon cancer $(10,11)$. To complement the relevant clinical data, the present study applied glycosylation methylation-specific polymerase chain reaction methods to check the $\mathrm{CpG}$ island methylation percentage for colon cancer, colorectal adenomas and normal colonic mucosa Runx3 gene, in order to explore the function of the $\mathrm{CpG}$ island methylation of the Runx3 gene in colon cancer.

\section{Materials and methods}

Tissue sample collection. The study was approved and registered by the Ethics Committee of Sichuan Provincial People's Hospital (Sichuan, China) in July 2008. The Ethics Committee approved the screening, treatment and data collection of these patients, and all the subjects provided written informed consent. All the studies were undertaken following the provisions of the Declaration of Helsinki.

In total, 68 surgical resection of colon cancer and adenomatous tissue samples were collected from Sichuan Provincial People's Hospital between October 2008 and February 2009.

The 68 patients were all first diagnosis and underwent treatment with preoperative radiotherapy, chemotherapy or immunotherapies, in which 34 cases were of colorectal adenoma and 34 cases were of colon cancer. A total of 34 healthy cases were normal tissue biopsy specimens under colonoscopy, and used as the negative control. The collection of new fresh tissue specimens was stored in liquid nitrogen within $20 \mathrm{~min}$ at $-183^{\circ} \mathrm{C}$. A total of 8 males and 16 females provided the colon cancer samples, and were aged from $38-78$ years (mean age, $58 \pm 2.5$ years). A total of 7 males and 
17 females, aged from 28-73 years (mean age, $53 \pm 2.7$ years), provided the colonic adenoma samples. The normal colon mucosa samples were provided from 18 males and 16 females, aged from 38-78 years (mean age, $58 \pm 2.2$ years).

The TIANamp Genomic DNA kit was purchased from Tiangen Biotechnology Co., Ltd., (Beijing, China), and the EZ DNA Methylation-Gold ${ }^{\mathrm{TM}}$ kit was from Rimo Science and Technology Development Co., Ltd., (Beijing, China). DNA markers $\lambda$ DNA/HindIII, 50-bp DNA Labber and $2 X$ Taq polymerase chain reaction (PCR) MasterMix were from Tiangen Technology Co., Ltd. The rabbit anti-human monoclonal antibody Runx3 was from Abcam (ab40278; Cambridge, MA, USA); and the DAB kit was from Zhongshan Golden Bridge Biological Technology Co., Ltd. (Beijing, China).

Primer synthesis and preparation. The DNA sequences were as reported in GenBank, and the PCR primers were designed according to the study by Issa (12). The primers were as follows: Runx3 methylation front guide sequences [methylated-specific forward (MF)], 5'-TTACGAGGGGCGGTC GTACGCGGG-3' and methylated reverse primer sequence [methylated-specific reverse (MR)], 5'-AAAACGACCGAC GCGAACGCCTCC-3'; Runx3 unmethylated front guide sequences (unmethylated-specific forward primers), 5'-TTA TGAGGGGTGGTTGTATGTGGG-3' and reverse primer sequence (unmethylated-specific reverse primers), 5'-AAA ACAACCAACACAAACACCTCC-3'.

DNA extraction. The present study referred to Herman et al (13) for the MSP methods. The TIANamp Genomic DNA kit was used to extract tissue sample DNA. The EZ DNA Methylation-Gold kit was used for the methylation-extracted tissue. The DNA Runx3M system included $12.5 \mu 12 \mathrm{X}$ Taq PCR MasterMix, $1 \mu \mathrm{l}$ Runx3 MF and $1 \mu 1$ Runx3 MR methylation.

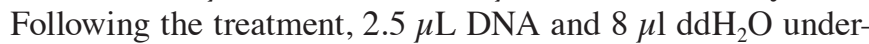
went the following Run 33 gene PCR conditions: denaturation at $94^{\circ} \mathrm{C}$ for $10 \mathrm{~min}$, annealing at $65^{\circ} \mathrm{C}$ for $45 \mathrm{sec}$, and extension at $72^{\circ} \mathrm{C}$ for $10 \mathrm{~min}$. The PCR products were applied to $1 \%$ agarose gel electrophoresis and gel images were captured using the Gel Doc 1000 imager (Bio-Rad, Hercules, CA, USA).

Immunohistochemical detection of the expression of Runx3 proteins. The Runx 3 antigen retrieval underwent a high-pressure hot fix. Phosphate-buffered saline solution was used instead of a primary antibody for the negative control. A known positive plate was used as a positive control.
Table I. Percentage of Runx3 CpG island methylation.

\begin{tabular}{lcr}
\hline & \multicolumn{2}{c}{ Runx3 CpG island methylation, \% } \\
\cline { 2 - 3 } Groups & Positive, $\mathrm{n}$ & Negative \\
\hline Colon cancer & 23.5 & 76.5 \\
Adenoma & 20.6 & 79.4 \\
Normal tissue & 0.0 & 100.0 \\
\hline
\end{tabular}

Runx3, runt-related transcription factor 3; negative, detection of unmethylated product, but not methylation-specific PCR product.

Table II. Percentage of Runx3 protein expression.

\begin{tabular}{lcc}
\hline & \multicolumn{2}{c}{ Runx3 protein expression, \% } \\
\cline { 2 - 3 } Groups & Positive & Negative \\
\hline Colon cancer & 17.6 & 82.4 \\
Adenoma & 61.8 & 38.2 \\
Normal tissue & 76.5 & 23.5 \\
\hline
\end{tabular}

Runx3, runt-related transcription factor 3; negative, $<10 \%$ of nucleus was brown/yellow.

Criteria. Noticeable methylated-specific PCR products at $250 \mathrm{bp}$ indicated positive methylation. Negative was the presence of a 240-bp unmethylated band, but no band for the methylated-specific PCR product (13). Following IHC staining, when $>10 \%$ of the whole section was brown/yellow, this was deemed as positive.

Statistical analysis. Statistical analysis was used to compare the percentage of Fisher's exact probability. Statistical analysis was performed using statistical software SPSS 13.0 (SPSS, Inc., Chicago, IL, USA). Data processing used a test level of $\alpha=0.05$, and $\mathrm{P}<0.05$ was considered to indicate a statistically significant difference.

\section{Results}

Runx 3 gene promoter $C p G$ island methylation. The percentage of Runx 3 promoter $\mathrm{CpG}$ island methylation positive expression in the colon carcinomas and adenomas were $23.5(8 / 34)$ and
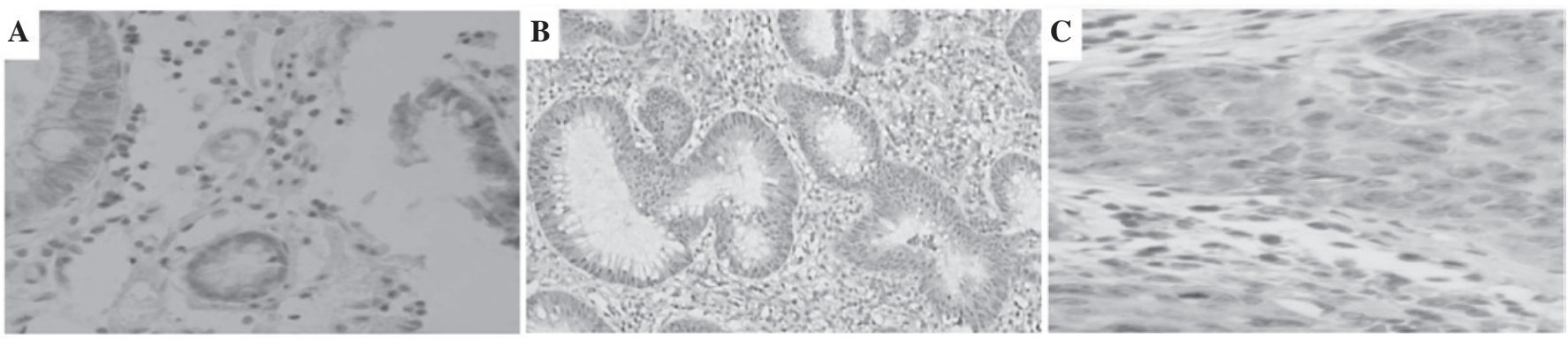

Figure 1. Expression level of runt-related transcription factor 3 (Runx3) in colon tissue in (A) normal mucosa adenoma tissue, (B) adenoma tissue and (C) colon cancer tissue. Immunohistochemical assay was used to detect the expression of Runx3 (magnification, x100). 
$20.6 \%(7 / 34)$, and there was no detection in the normal tissue. The methylation of the Runx3 gene in the colon cancer and colon adenoma groups was significantly different from normal colon mucosa $(\mathrm{P}<0.05)$. However, there was no significant difference between colon cancer and colon adenoma $(\mathrm{P}>0.05$, Table I).

Runx3 protein. Runx3 protein expression percentages were $17.6(6 / 34), 61.8(21 / 34)$ and $76.5 \%(26 / 34)$ in the colorectal cancer, adenoma and normal groups, respectively. There was a significant difference between the colon cancer and the colon adenoma and normal groups $(\mathrm{P}<0.05$, Table II, Fig. 1).

\section{Discussion}

DNA methylation is closely associated with tumorigenesis, which is one of the inactivation mechanisms of the tumor-suppressor genes (14). The Runx3 gene is a newly discovered suppressor oncogene, which is the most primitive Runx alkylene type in the mammalian gene family, and it has a regulatory effect on epithelial cell growth and differentiation. It also plays an important role in the spinal ganglia development and differentiation of T cells. The Runx3 protein is involved in the TGF- $\beta$ signal transduction pathway of a transcription factor, which is directly combined with Smad receptor binding. The protein guides the TGF- $\beta 1 / \mathrm{Smad}$ signaling pathway to activate Smad (one type of apoptotic factor). The complex moves from the cytoplasm into the nucleus of the target site, and the TGF- $\beta 1$ Smad complexes and target sites combine to promote TGF- $\beta 1$ signaling to mediate apoptosis in normal cells. Synergistic action of TGF- $\beta 1$ on epithelial cell growth has a negative regulation, which occurs in the TGF- $\beta 1$ signaling pathway and plays a key role (15). A previous study found that for the Runx3 gene colon cancer hypermethylation, the Runx3 CpG island methylation guides Runx3-induced gene inactivation, which is closely associated with colon cancer (16). Runx3 protein deficiencies can lead to the TGF- $\beta 1$ signaling pathway blocking TGF- $\beta 1$-induced cell growth inhibition, which reduces the sensitivity to apoptosis. $\beta$-catenin accumulates in the cytoplasm resulting in signal pathway activation, cell proliferation and apoptosis imbalance. The genetically unstable cancerous cell clonal expansion promotes the occurrence of tumors (17). Runx3 gene-knockout mice, which have decreased Runx 3 protein expression, significantly increased the incidence of tumors in mice (18). Ku et al (19) applied the MSP technique for detecting methylation in human colon cancer cell lines and found that $50 \%$ of human colon cancer cell line expression of Runx3 was decreased or there was no expression. The study also found that compared with the positive expression percentage of corresponding normal tissue, the percentage of Runx3 protein expression was significantly decreased in human colon cancer, liver cell cancer, bile duct cancer, pancreatic cancer, lung cancer, esophageal cancer, endodermal sinus tumors, breast (20-27) and other tumors.

In the present study, 8 cases of Runx $3 \mathrm{CpG}$ island methylation were found in 34 cases of colon cancer. Methylation was therefore $23.5 \%(8 / 34)$, and $\mathrm{Ku}$ et al (19) reported that there is an $18.4 \%$ methylation rate on the Runx $3 \mathrm{CpG}$ island in colon cancer, while there is no Runx 3 methylation in normal colon tissue. Goel et al (28) also identified 20.8\% (19/91) of the presence of Runx3 CpG island methylation in colon cancer cases, and no methylation was found in the normal group; these two studies show close and similar results with our present study. The present study identified that the Runx3 protein expression percentage was $76.5 \%(26 / 34)$ in normal colonic mucosa, $61.8 \%(21 / 34)$ in the adenoma group, and $17.6 \%$ $(6 / 34)$ in the colon cancer group. The colon adenoma group was significantly lower than the colon cancer group, and there was a significant difference $(\mathrm{P}<0.05)$. Chen et al $(27)$ reported similar results, which suggests that Runx3 CpG island methylation may occur in normal colonic mucosa transforming into colon gland adenoma. This may be an early stage of development in the cancer sequence, and the colon cancer early onset molecular events and low expression of Runx 3 protein may be associated with colon Runx3 CpG island methylation.

\section{References}

1. Esteller M: DNA methylation and cancer therapy: New developments and expectations. Curr Opin Oncol 17: 55-60, 2005.

2. Lewandowska $\mathbf{J}$ and Bartoszek A: DNA methylation in cancer development, diagnosis and therapy - multiple opportunities for genotoxic agents to act as methylome disruptors or remediators. Mutagenesis 26: 475-487, 2011

3. Xia Y, Zhang M, Zhang X and Liu X: A systematic review and meta-analysis of runt-related transcription factor 3 gene promoter hypermethylation and risk of gastric cancer. J Cancer Res Ther 10 (Suppl): 310-313, 2014.

4. Pellacani D, Kestoras D, Droop AP, Frame FM, Berry PA, Lawrence MG, Stower MJ, Simms MS, Mann VM, Collins AT, et al: DNA hypermethylation in prostate cancer is a consequence of aberrant epithelial differentiation and hyperproliferation. Cell Death Differ 21: 761-773, 2014.

5. Wojdacz TK, Windeløv JA, Thestrup BB, Damsgaard TE, Overgaard $\mathrm{J}$ and Hansen L: Identification and characterization of locus-specific methylation patterns within novel loci undergoing hypermethylation during breast cancer pathogenesis. Breast Cancer Res 16: R17, 2014.

6. Friedrich MJ, Rad R, Langer R, et al: Lack of RUNX3 regulation in human gastric cancer. J Pathol 210: 141-146, 2006.

7. Chen LF: Tumor suppressor function of RUNX3 in breast cancer. J Cell Biochem 113: 1470-1477, 2012.

8. Lee CW, Chuang LS, Kimura S, et al: RUNX3 functions as an oncogene in ovarian cancer. Gynecol Oncol 122: 410-417, 2011.

9. Tsunematsu T, Kudo Y, Iizuka S, et al: RUNX3 has an oncogenic role in head and neck cancer. PloS One 4: e5892, 2009.

10. Li M, Tan SY, Zhang J and You HX: Effects of paeonol on intracellular calcium concentration and expression of RUNX3 in LoVo human colon cancer cells. Mol Med Rep 7: 1425-1430, 2013.

11. Slattery ML, Lundgreen A, Herrick JS, Caan BJ, Potter JD and Wolff RK: Associations between genetic variation in RUNX1, RUNX2, RUNX3, MAPK1 and eIF4E and risk of colon and rectal cancer: additional support for a TGF- $\beta$-signaling pathway. Carcinogenesis 32: 318-326, 2011.

12. Issa JP: CpG island methylator phenotype in cancer. Nat Rev Cancer 4: 988-993, 2004.

13. Herman JG, Graff JR, Myöhänen S, Nelkin BD and Baylin SB: Methylation-specific PCR: A novel PCR assay for methylation status of CpG islands. Proc Natl Acad Sci USA 93: 9821-9826, 1996.

14. Esteller M, Corn PG, Baylin SB and Herman JG: A gene hypermethylation profile of human cancer. Cancer Res 61: 3225-3229, 2001 .

15. Vogelmann R, Nguyen-Tat MD, Giehl K, Adler G, Wedlich D and Menke A: TGFbeta-induced downregulation of E-cadherin-based cell-cell adhesion depends on PI3-kinase and PTEN. J Cell Sci 118: 4901-4912, 2005.

16. Subramaniam MM, Chan JY, Soong R, Ito K, Yeoh KG, Wong R, Guenther T, Will O, Chen CL, Kumarasinghe MP, et al: RUNX3 inactivation in colorectal polyps arising through different pathways of colonic carcinogenesis. Am J Gastroenterol 104: 426-436, 2009.

17. Miyazono K, Maeda S and Imamura T: Coordinate regulation of cell growth and differentiation by TGF-beta superfamily and Runx proteins. Oncogene 23: 4232-4237, 2004. 
18. Soong R, Shah N, Peh BK, Chong PY, Ng SS, Zeps N, Joseph D, Salto-Tellez M, Iacopetta B and Ito Y: The expression of RUNX3 in colorectal cancer is associated with disease stage and patient outcome. Br J Cancer 100: 676-679, 2009.

19. Ku JL, Kang SB, Shin YK, Kang HC, Hong SH, Kim IJ, Shin JH, Han IO and Park JG: Promoter hypermethylation downregulates RUNX3 gene expression in colorectal cancer cell lines. Oncogene 23: 6736-6742, 2004.

20. Li QL, Ito K, Sakakura C, Fukamachi H, Inoue K, Chi XZ, Lee KY, Nomura S, Lee CW, Han SB, et al: Causal relationship between the loss of RUNX3 expression and gastric cancer. Cell 109: 113-124, 2002.

21. Park WS, Cho YG, Kim CJ, Song JH, Lee YS, Kim SY, Nam SW, Lee SH, Yoo NJ and Lee JY: Hypermethylation of the RUNX3 gene in hepatocellular carcinoma. Exp Mol Med 37: 276-281, 2005.

22. Kim WJ, Kim EJ, Jeong P, Quan C, Kim J, Li QL, Yang JO Ito $\mathrm{Y}$ and Bae SC: RUNX3 inactivation by point mutations and aberrant DNA methylation in bladder tumors. Cancer Res 65: 9347-9354, 2005.

23. Sato K, Tomizawa Y, Iijima H, Saito R, Ishizuka T, Nakajima T and Mori M: Epigenetic inactivation of the RUNX3 gene in lung cancer. Oncol Rep 15: 129-135, 2006.
24. Hiramatsu T, Osaki M, Ito Y, Tanji Y, Tokuyasu N and Ito $\mathrm{H}$ Expression of RUNX3 protein in human esophageal mucosa and squamous cell carcinoma. Pathobiology 72: 316-324, 2005.

25. Vogiatzi P, De Falco G, Claudio PP and Giordano A: How does the human RUNX3 gene induce apoptosis in gastric cancer? Latest data, reflections and reactions. Cancer Biol Ther 5: 371-374, 2006.

26. Kato N, Tamura G, Fukase M, Shibuya H and Motoyama T: Hypermethylation of the RUNX3 gene promoter in testicular yolk sac tumor of infants. Am J Pathol 163: 387-391, 2003.

27. Chen W, Salto-Tellez M, Palanisamy N, Ganesan K, Hou Q, Tan LK, Sii LH, Ito K, Tan B, Wu J, et al: Targets of genome copy number reduction in primary breast cancers identified by integrative genomics. Genes Chromosomes Cancer 46: 288-301, 2007.

28. Goel A, Arnold CN, Tassone P, Chang DK, Niedzwiecki D, Dowell JM, Wasserman L, Compton C, Mayer RJ, Bertagnolli MM, et al: Epigenetic inactivation of RUNX3 in microsatellite unstable sporadic colon cancers. Int J Cancer 112: 754-759, 2004. 